\title{
Prevalence of hepatocellular carcinoma in the entire Fontan population of Australia and New Zealand
}

Thomas G. Wilson, BSc, MD, ${ }^{\mathrm{a}, \mathrm{b}}$ Ajay J. Iyengar, MBBS, PhD, FRACS, ${ }^{\mathrm{a}, \mathrm{c}}$

Winita Hardikar, MBBS, FRACP, PhD, FAASLD, ${ }^{\text {b,d }}$ Siddharth Sood, MBBS, BMedSci, PhD, ${ }^{\mathrm{e}}$ and Yves d'Udekem, MD, $\mathrm{PhD}^{\mathrm{a}, \mathrm{b}, \mathrm{c}}$

\footnotetext{
From the ${ }^{\mathrm{a} H e a r t}$ Research Group, Murdoch Children's Research Institute; ${ }^{\mathrm{b}}$ Faculty of Medicine, Department of Paediatrics, The University of Melbourne; Departments of ${ }^{\mathrm{C}}$ Cardiac Surgery and dGastroenterology, The Royal Children's Hospital; and ${ }^{\mathrm{e}}$ Department of Gastroenterology and Hepatology, The Royal Melbourne Hospital, Melbourne, Australia.

Dr Iyengar is the recipient of an Edwards LifeSciences Educational Grant. Dr Wilson is the recipient of a National Health and Medical Research Council (NHMRC) Postgraduate Scholarship (GNT1168270).

Disclosures: Dr d'Udekem is a consultant for MSD and Actelion. All other authors reported no conflicts of interest. The Journal policy requires editors and reviewers to disclose conflicts of interest and to decline handling or reviewing manuscripts for which they may have a conflict of interest. The editors and reviewers of this article have no conflicts of interest.

Received for publication Jan 9, 2020; revisions received Jan 9, 2020; accepted for publication March 8, 2020; available ahead of print April 9, 2020.

Address for reprints: Yves d'Udekem, MD, PhD, Department of Cardiac Surgery, Royal Children's Hospital, Flemington Rd, Parkville 3052, Australia (E-mail: yves.dudekem@rch.org.au).

JTCVS Techniques 2020;2:128-30

2666-2507

Copyright (c) 2020 The Authors. Published by Elsevier Inc. on behalf of The American Association for Thoracic Surgery. This is an open access article under the CC BY-NC-ND license (http://creativecommons.org/licenses/bync-nd/4.0/).

https://doi.org/10.1016/j.xjtc.2020.03.008
}

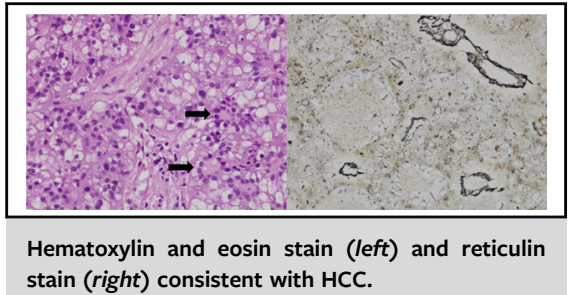

CENTRAL MESSAGE

The prevalence of hepatocellular carcinoma in the Australia and New Zealand Fontan Registry is $0.3 \%$ (mean follow-up of 12.7 years)

See Commentaries on pages 131 and 133 .
Hepatic fibrosis, cirrhosis, and hepatocellular carcinoma (HCC) are now well recognized as complications of Fontan palliation. ${ }^{1,2}$ The occurrence of HCC in particular has caused alarm among clinicians, patients, and families, with high mortality rates reported following diagnosis. ${ }^{3}$ Although many cases of HCC after Fontan are now described in the literature, the population-based prevalence of this complication is not known.

The Australian and New Zealand Fontan Registry is a population-based, binational Registry that collects the follow-up data of all patients who have undergone a Fontan procedure in the region. Between June 3, 1975, and December 31, 2018, a total of 1620 patients underwent and survived a Fontan procedure in Australia and New Zealand. Sixty-eight patients $(4 \%)$ were not consented to participate in the Registry. The mean follow-up time of consented patients was 12.7 years. Of those consented and followed by the Registry, 5 patients $(0.3 \%)$ were diagnosed with HCC (equivalent to approximately 1 case per 4000 years of follow-up) (Table 1).

Patient 1, a 36-year-old woman with known hepatic cirrhosis and ascites, was identified to have innumerable hepatic lesions on a quad-phase computed tomography (CT) scan performed in the context of an acute illness with abdominal pain and coagulopathy. Liver biopsy showed moderately differentiated HCC (Figure 1) and an occlusive tumor thrombus in the left portal vein. She was commenced on sorafenib, a tyrosine kinase inhibitor, but had further hepatic decompensation. She was referred to palliative care.

Patient 2, a 25-year-old woman with known portal hypertension with gastric and esophageal varices, was diagnosed with HCC based on imaging. A routine surveillance ultrasound demonstrated features of hepatic fibrosis and liver nodularity, and a CT scan identified 2 lesions characteristic of HCC. An initial liver biopsy taken from adjacent tissue was nondiagnostic, and a second liver biopsy following laparoscopic microwave ablation of the lesions remained inconclusive. Repeat CT scan following ablation showed an overall reduction in the size of the 2 lesions.

Patient 3, a 13-year-old girl with a history of recurrent atrial arrhythmias and severe pulmonary and tricuspid regurgitation before undergoing a Fontan procedure, was diagnosed with HCC after presenting to hospital with abdominal pain and fevers. A CT scan showed evidence of multinodular cirrhosis and numerous lesions suggestive of HCC. The diagnosis was confirmed on liver biopsy. She underwent chemoembolization, with subsequent liver transplantation performed at 3 months following diagnosis. Tumor recurrence was noted in the transplanted graft in the months following discharge, and she died within 12 months of transplantation. ${ }^{4}$

Patient 4, a 32-year-old man with known cirrhosis and portal hypertension, was diagnosed with HCC following 
TABLE 1. Patient characteristics

\begin{tabular}{|c|c|c|c|c|c|}
\hline $\begin{array}{l}\text { Patient } \\
\text { no. }\end{array}$ & $\begin{array}{c}\text { Primary } \\
\text { morphologic } \\
\text { diagnosis }\end{array}$ & Previous procedures & Age at Fontan, $y$ & $\begin{array}{c}\text { Fontan type } \\
\text { (+ concomitant procedures) }\end{array}$ & $\begin{array}{c}\text { Cardiac } \\
\text { reinterventions }\end{array}$ \\
\hline 1 & TA, VSD & PDA ligation, PA banding & 3 & $\begin{array}{l}\text { Bjork modification } \\
\text { Conversion to ECC, } \\
\text { non-fenestrated }\end{array}$ & $\begin{array}{l}\text { Dual-chamber } \\
\text { pacemaker insertion }\end{array}$ \\
\hline 2 & ccTGA, DILV & $\begin{array}{l}\text { PA banding, aortic arch } \\
\text { reconstruction; Damus } \\
\text { procedure, BCPS }\end{array}$ & 4 & ECC, non-fenestrated & $\begin{array}{l}\text { Dual-chamber } \\
\text { pacemaker insertion }\end{array}$ \\
\hline 3 & PA-IVS & $\begin{array}{l}\text { RVOT transannular patch, } \\
\text { side-to-side anastomosis } \\
\text { between RPA and SVC, } \\
\text { ASD closure, PDA ligation }\end{array}$ & 12 & $\begin{array}{l}\text { ECC, fenestrated ( }+ \text { tricuspid } \\
\text { valve closure }) \\
\quad(+ \text { pulmonary valve repair }) \\
(+ \text { Cox-maze procedure })\end{array}$ & $\begin{array}{l}\text { Dual-chamber } \\
\text { pacemaker insertion }\end{array}$ \\
\hline 4 & TA, VSD & BT shunt & 5 & $\begin{array}{l}\text { AP Conversion to ECC, } \\
\text { non-fenestrated }\end{array}$ & $\begin{array}{l}\text { Dual-chamber pacemaker } \\
\text { insertion, Cox-maze } \\
\text { procedure, pulmonary } \\
\text { artery reconstruction }\end{array}$ \\
\hline 5 & ccTGA, MA & None & 22 & $\mathrm{AP}(+$ closure of atrial septal defect $)$ & None \\
\hline
\end{tabular}

$T A$, Tricuspid atresia; $V S D$, ventricular septal defect; $P D A$, patent ductus arteriosus; $P A$, pulmonary artery; $E C C$, extracardiac conduit; $c c T G A$, congenitally-corrected transposition of the great arteries; $D I L V$, double-inlet left ventricle; $B C P S$, bidirectional cavopulmonary shunt; PA-IVS, pulmonary atresia with intact ventricular septum; RVOT, rightventricular outflow tract; $R P A$, right pulmonary artery; $S V C$, superior vena cava; $A S D$, atrial septal defect; $B T$, Blalock-Taussig; $A P$, atriopulmonary; $M A$, mitral atresia.

an abdominal ultrasound identifying a large hepatic lesion. A CT scan showed locally invasive HCC, and a subsequent liver biopsy confirmed the diagnosis. He was treated palliatively with oral sorafenib and died in the hospital 6 months after diagnosis.

Patient 5, a 44-year-old woman with known liver cirrhosis and ascites, was incidentally found to have a focal liver lesion during cholecystectomy. A CT scan identified hepatomegaly with features of cirrhosis and portal hypertension, and a single lesion consistent with HCC. A targeted liver biopsy confirmed the diagnosis. She underwent a partial left hepatic lobectomy; however, she died 6 weeks following surgery after a complicated postoperative course.

This is the first population-based report of HCC prevalence in patients who underwent a Fontan procedure. Although undoubtedly a serious potential complication of Fontan palliation, the overall prevalence of HCC in the
Australia and New Zealand Fontan population is low. Features unique to our region, including a relatively late uptake of the Fontan procedure and a smaller proportion of patients with hypoplastic left heart syndrome, may account for the low prevalence that we have observed. However, this observation is reassuring in comparison with previous reports of HCC prevalence of up to $4 \%$ in small, non-populationbased cohorts of adult patients who had undergone a Fontan procedure. ${ }^{3,5}$

Not surprisingly, all patients with HCC had clear clinical evidence of cirrhosis and portal hypertension, suggesting that screening might best be directed at patients with these complications. Screening for HCC is well established for patients with cirrhosis caused by other chronic liver diseases such as viral hepatitis, and these protocols could be adapted for patients with a Fontan circulation. This also seems to be a complication with a predilection for those

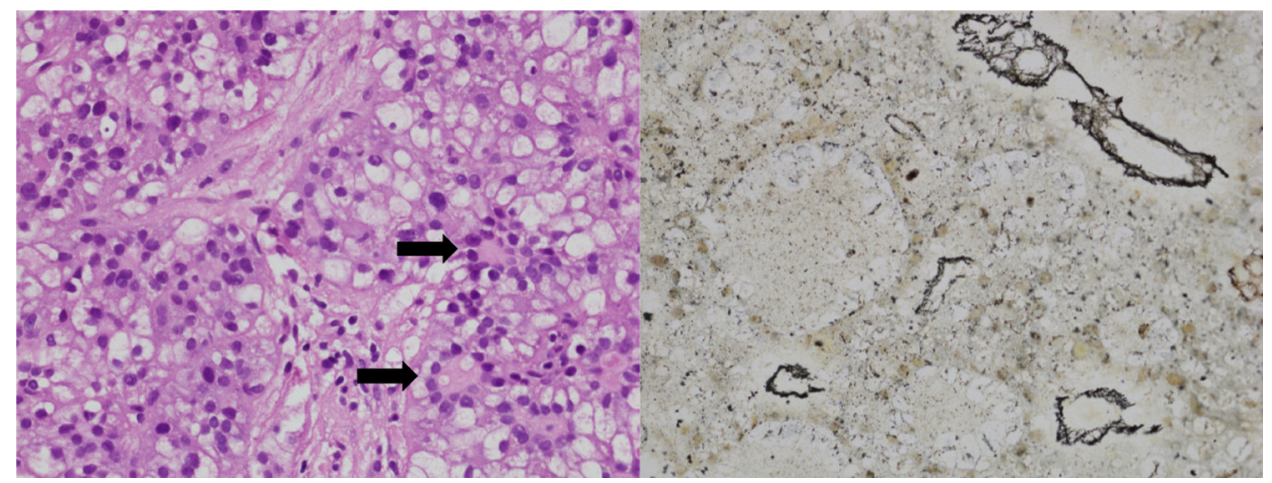

FIGURE 1. Hematoxylin and eosin stain (left): tumor cells forming solid nests and some acinar structures (arrows); cells have enlarged pleomorphic nuclei and mitoses are present. Reticulin stain (right): extensive loss of the reticulin network consistent with hepatocellular carcinoma. 
with a history of long-term circulatory dysfunction, with 4 of the 5 patients having undergone reintervention for management of cardiac arrythmias. More prudent recognition and management of the failing Fontan may result in a progressive reduction in the incidence of HCC in Fontan patients over time. Additional population-based reports will aid in confirming the prevalence of this complication and may help to identify those requiring more intensive liver surveillance.

The authors thank the Murdoch Children's Research Institute for infrastructure support. The authors also acknowledge the Fontan Registry management and research assistants for their invaluable support in the creation and maintenance of the Registry.
The authors would like to acknowledge Dr Karin Du Plessis for her role in data gathering for this publication.

\section{References}

1. Rychik J, Veldtman G, Rand E, Russo P, Rome JR, Krok K, et al. The precarious state of the liver after a Fontan operation: summary of a multidisciplinary symposium. Pediatr Cardiol. 2012;33:1001-12.

2. Asrani SK, Warnes CA, Kamath PS. Hepatocellular carcinoma after the Fontan procedure. N Engl J Med. 2013;368:1756-7.

3. Egbe AC, Poterucha JT, Warnes CA, Connolly HM, Baskar S, Ginde S, et al. Hepatocellular carcinoma after Fontan operation. Circulation. 2018;138:746-8.

4. Rosenbaum J, Vrazas J, Lane GK, Hardikar W. Cardiac cirrhosis and hepatocellular carcinoma in a 13-year-old treated with doxorubicin microbead transarterial chemoembolization. J Paediatr Child Health. 2012;48:E140-3.

5. Nandwana SB, Olaiya B, Cox K, Sahu A, Mittal P. Abdominal imaging surveillance in adult patients after Fontan procedure: risk of chronic liver disease and hepatocellular carcinoma. Curr Prob Diagn Radiol. 2018;47:19-22. 